\title{
DC-AC power inverter controlled analogically with zero hysteresis
}

Fredy E. Hoyos Velasco ${ }^{1}$, Carlos I. Hoyos Velasco ${ }^{2}$, John E. Candelo-Becerra ${ }^{3}$

${ }^{1}$ Facultad de Ciencias, Escuela de Física, Universidad Nacional de Colombia, Sede Medellín, Colombia

${ }^{2}$ Italian National Research Council, Engine Institute, Italy

${ }^{3}$ Facultad de Minas, Departamento de Energía Eléctrica y Automática, Campus Robledo, Universidad Nacional de Colombia, Sede Medellín, Colombia

\begin{tabular}{l}
\hline \hline Article Info \\
\hline Article history: \\
Received Feb 22, 2019 \\
Revised Jun 6, 2019 \\
Accepted Jun 27, 2019 \\
\hline Keywords: \\
Buck converter \\
DC-AC inverter \\
Feedback control \\
Signal generator \\
Zero hysteresis \\
\hline
\end{tabular}

\begin{abstract}
This paper presents the design and experimental validation of a DC-AC power inverter, controlled analogically with zero hysteresis. A control circuit was built using analog electronics components, and optocoupler devices are used to couple the control module with the power stage. The design of DC$\mathrm{AC}$ inverter with electronics circuit and implementation are shown in detail. Experimental results show the effectiveness of control technique and implementation, leading to a robust system concerning load disturbances. The developed inverter offers the possibility of generating regulated output voltages of different signal types, both $\mathrm{DC}$ and $\mathrm{AC}$, variable in frequency and in amplitude, useful for feeding a load with various AC signals.
\end{abstract}

Copyright (C) 2019 Institute of Advanced Engineering and Science. All rights reserved.

\section{Corresponding Author:}

Fredy E. Hoyos Velasco, Facultad de Ciencias, Escuela de Física, Universidad Nacional de Colombia, Sede Medellín, Carrera 65 No. 59A - 110 Medellín 050034, Colombia. Email: fehoyosve@unal.edu.co

\section{INTRODUCTION}

Industrial applications require that voltage supplied to electrical loads maintains good regulation capability while being cheaper and efficient [1]. It is estimated that $90 \%$ of electrical energy is processed through power converters before their final use [2]. The bad regulation generates in the equipment significant damages in its internal components, loss of information, and bad operation [3].

A power inverter is a device that transforms the electrical signals from direct current (DC) to alternate current (AC) to fulfill a specific task. Power inverters are used today because they offer efficiency, safety, reliability, low cost, smaller size, and provide a regulated voltage level that allows working in complex environments where it was challenging. Critical loads such as digital circuits, UPS, electric soldering irons, telephone exchanges, photocopiers, among others, require the use of electronic converters for their operation. The most desirable qualities in these devices are their robustness to load variations and performance efficiency, which can be optimized through the use of controlled switching devices as solid state switching devices [4].

Power inverters are used in microgrid $[5,6]$ to transfer electrical energy from direct to alternating current (DC-AC) [7], as shown in Figure 1. This can be modeled as a piecewise linear system with three topologies [8]. A complete introduction to power converters can be found in [9]. However, as different types of loads are typically connected to these converters [10], some significant voltage variations are presented in the network [11]. 


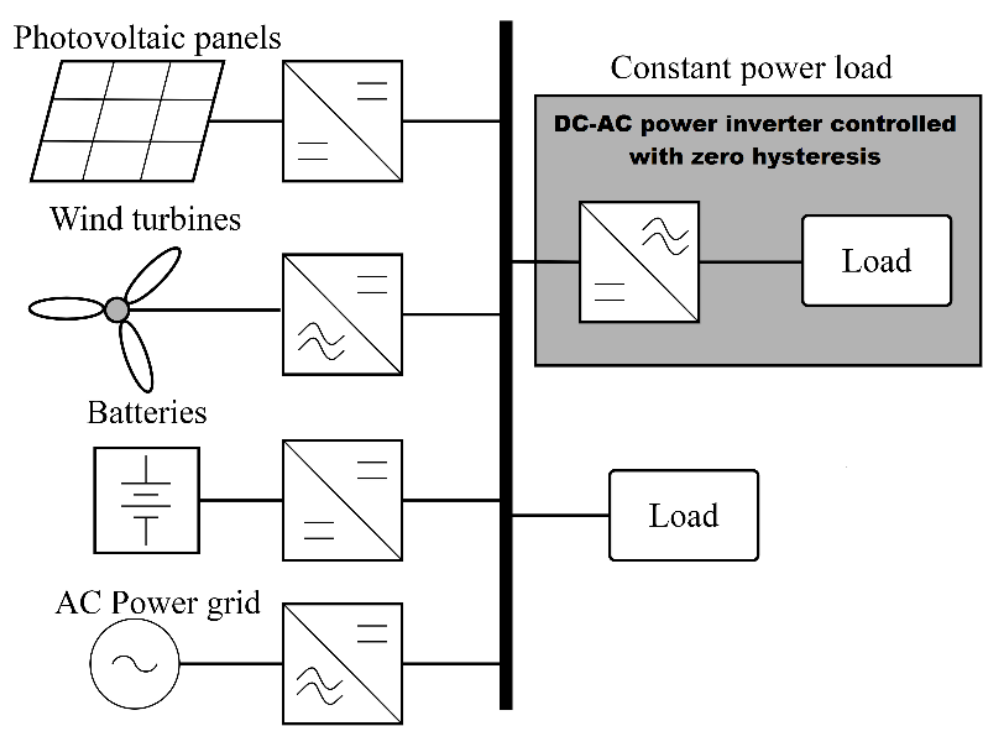

Figure 1. Power inverter with zero hysteresis used in a microgrid

There are many theoretical and experimental works on different control techniques applied to the design of a DC-AC converter. For example, in [2] and [12], the DC-AC buck converter was studied using simulations with ZAD control techniques [13] and FPIC [14]. In [8, 15] a DC-AC buck converter controlled with the ZAD technique was experimentally designed. The design and construction of an experimental prototype of a DC-DC power converter controlled with zero hysteresis, capable of generating dc voltages, was designed in [16]. The method was tested by using simulation and experiments that show the functioning of the technique.

Numerical [17], analytical [18, 19], and experimental tests were also performed to validate the different responses of DC-DC converters [20, 21]. However, many of these works have been dedicated to showing the behavior of DC-DC converters, and only a few have focused on the design of DC-AC power converters. Hence, studies on the development of DC-AC power converters should be done more broadly, to identify the ways these converters respond in different operation conditions, and when load changes are presented in the system.

The construction of an experimental prototype of the voltage-regulated inverter, capable of producing various signals as a power generator that supplies AC or DC signals with variable frequency and voltage amplitudes is of great interest for education. Therefore, this paper presents the design and construction of DC-AC power inverter, configured in a closed loop and controlled analogically, capable of delivering a regulated voltage and defined by the user, both $\mathrm{AC}$ and $\mathrm{DC}$ at the output. Because it is a reducing voltage system, there will be a voltage output lower than the supply voltage, for the case under study the system is fed with $30 \mathrm{~V} \mathrm{DC}$. Tests were made changing resistive loads, obtaining good regulation for various signals such as sinusoidal, triangular, square, and others [12]. The rest of the paper is divided as follows: Section 2 presents the methods, Section 3 includes the results and analysis; and finally, Section 4 shows the conclusion and future research.

\section{RESEARCH METHOD}

There are many power converter topologies [4], which is broken down into two groups: those with dielectric insulation between their input and output (Buck, Boost, Buck-Boost, and Cuk) and those without (Flyback, Forward). This work presents the design of an electronic converter built with a buck converter.

\subsection{Mathematical modeling}

Figure 2 shows the basic scheme of a buck converter, which is fed with a DC voltage in either direction depending on the control signal given by the controller with zero hysteresis. This is responsible for calculating the time in that each of the sources will be connected, in such a way that a regulated voltage is delivered to the output. 


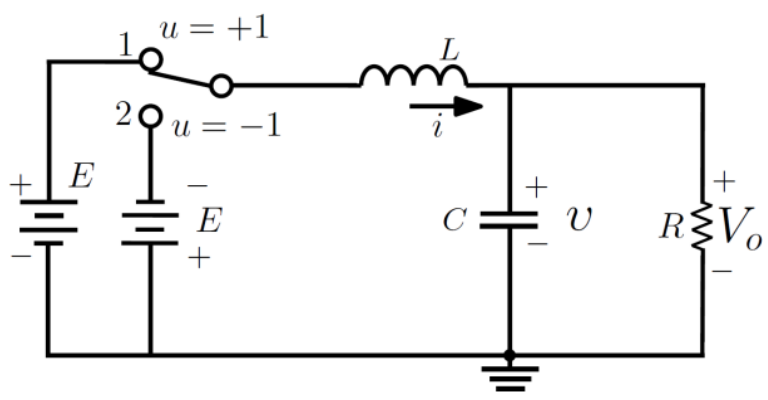

Figure 2. Basic circuit outline of a buck converter

If the reference signal is an alternating type, the converter will behave as a DC-AC converter. On the other side, if the reference signal is a continuous type, the power converter will behave as a DC-DC converter. Both cases act as a voltage reducer and this is due to physical limitations inherent to each of the devices that make up the system, with limitations in terms of switching frequency which affects the output of the system. Therefore, a control with zero hysteresis is proposed, forcing the converter to switch as fast as possible to have a regulated voltage at the output of the circuit.

The presence of a modulated control signal (control command ON or OFF) allows modeling the system as one of variable structure because it switches from one topology to another each time the control signal changes. This fact allows to introduce a controller based on zero hysteresis, where the user gives the reference signal, the voltage is measured at the output, the error is calculated, the control pulses are generated for different switches, and the filter and load are fed with $+E$ or $-E$. The state-space representation of the system extensively studied in [22, 23], is shown in (1).

$$
\begin{gathered}
{\left[\begin{array}{c}
\dot{v} \\
i
\end{array}\right]=\left[\begin{array}{cc}
-\frac{1}{R C} & \frac{1}{C} \\
-\frac{1}{L} & 0
\end{array}\right]\left[\begin{array}{l}
v \\
i
\end{array}\right]+\left[\begin{array}{l}
0 \\
\frac{E}{L}
\end{array}\right] u} \\
y=\left[\begin{array}{ll}
1 & 0
\end{array}\right] v
\end{gathered}
$$

This expression is then simplified as $\dot{x}=A x+B u$ and $y=C x$, because the control signal $u$ takes two values +1 and -1 . Then the system is nonlinear but smooth in sections, with two different linear topologies form by each sampling period.

\subsection{System configuration in closed loop}

Figure 3 shows the diagram of the system configured in a closed loop. In this case, the control action is generated when the error signal is processed by a comparator, which is equivalent to a control with zero hysteresis [16].

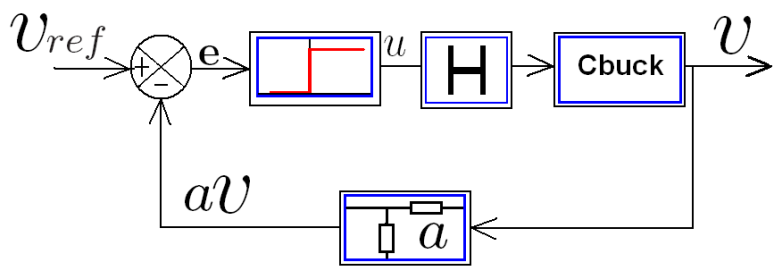

Figure 3. Block diagram of the system working in a closed loop

The error signal is calculated as shown in (2); where $a$ is the gain of the voltage sensor in charge of measuring the output voltage $v$ in the load or the capacitor, $v_{r e f}$ is the reference voltage, the control rule to implement aims at tracking the reference voltage $v_{r e f}$, achieving minimum regulation error.

$$
e=v_{r e f}-a v
$$


The strategy is described by (3), corresponding to a controlled system with zero hysteresis [24].

$$
\dot{x}= \begin{cases}A x+B u & \text { with } u=+1 \quad \text { when } e>0 \\ A x+B u & \text { with } u=-1 \quad \text { when } e<0\end{cases}
$$

For a buck converter designed to control voltage by zero hysteresis band, the system generates a regulated output without ripple, ideally, with the implication of an infinite switching frequency. However, from the experimental test, it is not possible to implement the control with ideal zero hysteresis, due to non-linearities, delays and dead times present in electronic components [16]. Thus, when configuring the system and trying to control it with zero hysteresis, it is expected that low ripple is presented at the output due to the existence of a natural hysteresis associated with the physical characteristics of the elements, which are not considered in the mathematical model.

\subsection{H bridge design}

An $\mathrm{H}$ bridge is an actuator that consists of 4 switches (Figure 4) driven by an activation logic, which switch in such a way that the converter is powered to $+E$ or $-E$, depending on the control signal $u$.

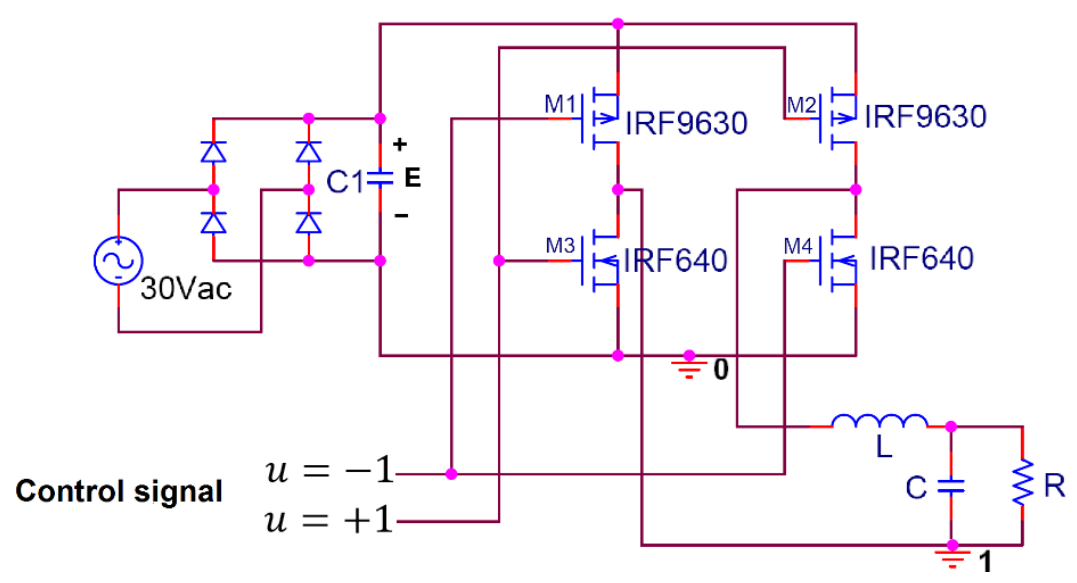

Figure 4. H-bridge circuit

The four switches are MOSFET transistors, where M1 and M2 are channel P, and M3 and M4 are channel $\mathrm{N}$. These transistors are put in cut or saturation using a control signal $u$, which determines how long the converter will be connected to the source $+E$ or $-E$ at the input of the converter.

\subsection{Activation circuits for $\mathbf{H}$-bridge transistors}

Figure 5 shows the electronic circuit used to perform the activation of the transistors. Thus, the filter $\mathrm{LC}$ of the buck converter is feed with voltage $+E$ or $-E$, as required.

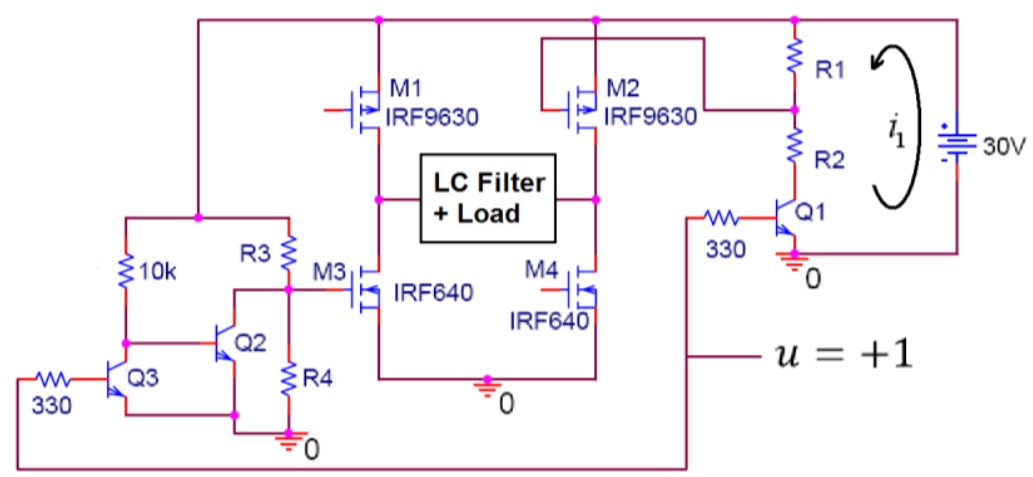

Figure 5. Circuit designed to activate the transistors used in $\mathrm{H}$-bridge 
When $u=+1$, the transistor Q1 goes into saturation which causes the current flowing from the source of $+30 \mathrm{~V}_{\mathrm{DC}}$ to ground, through $\mathrm{R} 1$ and $\mathrm{R} 2$, forming a voltage divider which polarizes the transistor M2 with a negative voltage $V_{G S}$. Applying the Kirchhoff's laws to the branch of $i_{1}$, the following expression is obtained: $E+i_{1} R_{1}+i_{1} R_{2}=0$ if $\mathrm{Q} 1$ is in saturation. Thus, the current can be expressed as in (4).

$$
i_{1}=\frac{E}{R_{1}+R_{2}}
$$

After considering $V_{G S}=-i_{1} R_{1}$, the expression in (5) is obtained:

$$
\frac{R_{1}}{R_{1}+R_{2}}=-\frac{V_{G S}}{E}
$$

To obtain an activation voltage $V_{G S}=-5 \mathrm{~V}$ when $R_{2}=300 \mathrm{k} \Omega$, then a resistance with a value of $R_{1}=6.6 \mathrm{k} \Omega$ is required. However, as this resistance value is not commercially found the following value is used for the test $R_{1}=6.8 \mathrm{k} \Omega$, which leads to $V_{G S}=-5.12 \mathrm{~V}$. Therefore, when there is a control pulse $u=+1$, it is possible to have $V_{G S}=-5.12 \mathrm{~V}$, which makes the transistor M2 be ON (in conduction mode); and when $u=-1$, then $V_{G S}=0 \mathrm{~V}$ and the transistor is OFF (no conduction mode).

The MOSFET IRF640 (channel N - M3) and transistor Q3 are activated when the signal $u=+1$. Therefore, the transistor Q2 is not activated and induces to the power transistor terminals $V_{G S}$ a positive voltage, created by the voltage divider equal to the voltage in $R_{4}$. As a result, transistor M3 enters in saturation due to the positive voltage $V_{G S}$. This case considers $V_{G S}=5.12 \mathrm{~V}$ with $R_{3}=33 \mathrm{k} \Omega$. The activation of $-E$ is the same, but in this case, the control signal is obtained. Similar activations are used for transistors M1 and M3 to obtain $-E$, when the control signal $u=-1$.

\subsection{Analog control circuit}

The control action is implemented using an analog control circuit. The voltage at the output is regulated to a reference $\mathrm{AC}$ or DC voltage given by the user because the voltage sensor includes a factor $\mathrm{a}=1 / 11$. Then, the reference voltage is scaled to the same units, to obtain values in the linear range of operational amplifiers $[-10,+10]$. Load voltage regulation at the output of the inverter is achieved by switching the power transistors, driven by error dynamics and synchronized correctly to avoid short circuits.

The control stage is shown in Figure 6, where the TL084CN operational amplifiers are polarized with $V^{+}=10$ and $V^{-}=-10$. The control action is computed using the error $(e)$, which is obtained by implementing the difference operator through an operational amplifier, where the inputs are the reference voltage $-10 \mathrm{~V} \leq v_{\text {ref }} \leq 10 \mathrm{~V}$ and the inverter output voltage (voltage in the load) $v$ conditioned with $a=1 \mathrm{~V} / 11 \mathrm{~V}$, so that they are in the same range. Using the scale factor $a$, it is possible to extend the control circuit to any range of output voltage, allowing to have a feedback signal $v_{\text {sensor }}$, admissible in the linear range of operational amplifiers.

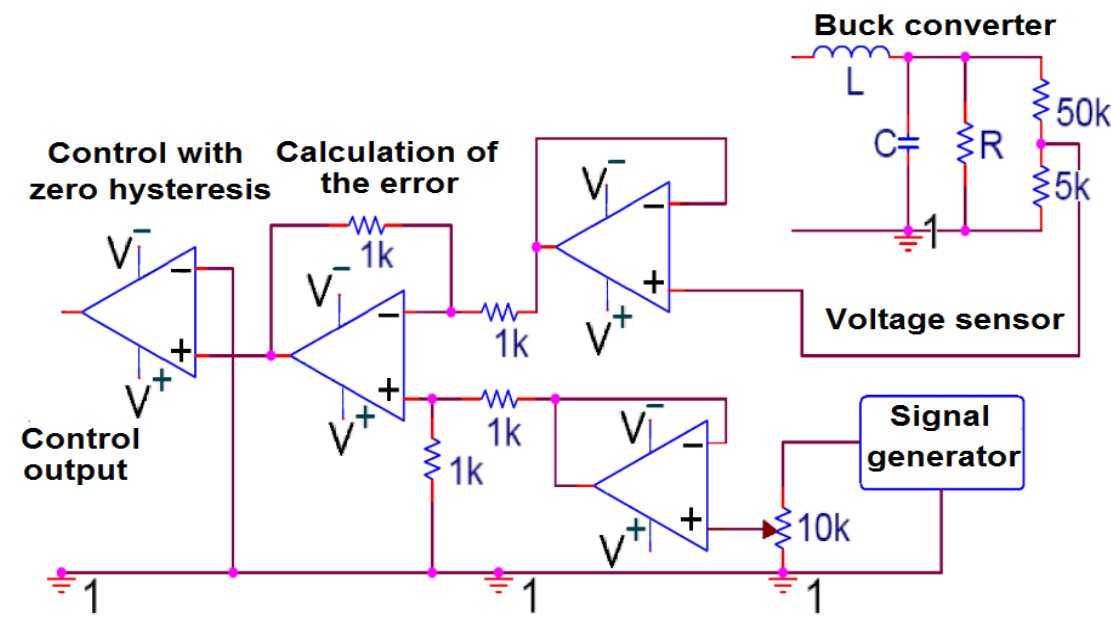

Figure 6. Analog control circuit to implement the zero-hysteresis control using operational amplifiers 
Additionally, an operational amplifier is used as a voltage follower to increase the input impedance of the control circuit, while keeping the voltage divider resistance invariant. Considering the tracking error computed as $e=v_{r e f}-a v$, authors also note that for experimental purposes, the reference voltage $v_{\text {ref }}$ is obtained from a signal generator, which corresponds to the desired voltage in the load scaled by the same factor $a$, that is $v_{\text {ref }}=a * v_{\text {desired }}$. Various signals are generated using the signal generator and applied in the analog controller also using a voltage follower. Reference inputs can include any shape, e.g. sinusoidal, square, ramp, triangular and others. So, the presented inverter also allows to transfer different signals to a load with the same time shape and frequency spectrum, of course with higher power and voltage levels, in other terms authors are proposing a system able to emulate a power signal generator, capable of being scaled to different power/voltage levels.

\subsection{Optocoupling of the control and power stages}

Control and power network requires adequate ground management [25] and coupling because the generator has one earth for the power part and another for the control. Therefore, the electronic circuit to solve the problem is shown in Figure 7, which functions to execute the switches of the H-bridge from the output of the control system. The grounds of the control and power stage have been labeled with indexes 1 and 0 , respectively.

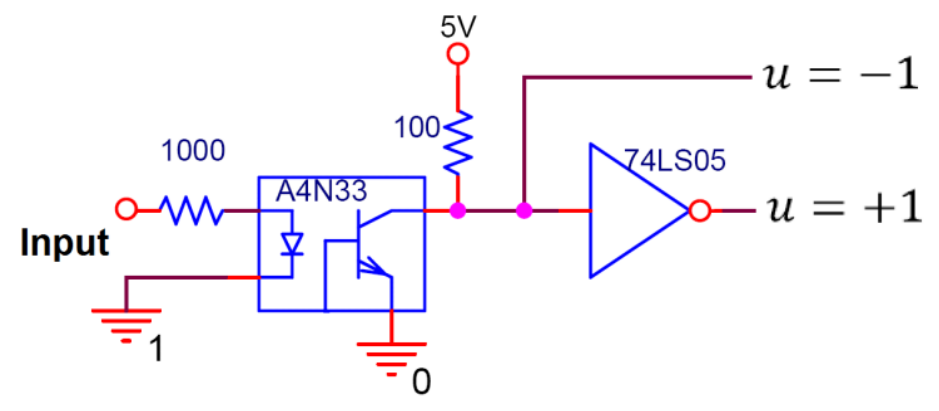

Figure 7. Opto-coupling circuit

\subsection{Current and voltage measurement}

It is necessary to have information about system state variables, for control purposes, system analysis and monitoring. Therefore, the load and inductor current were measured using Hall effect sensors. Furthermore, the capacitor voltage is measured using a voltage divider using resistors with factor $a=1 / 11$. Thus, it is possible to deal with $30 \mathrm{~V}$ or a higher voltage by scaling its value to a suitable range in the analog control circuit. Therefore, if a higher voltage level is preferred in the load, e.g. 180 volts peak to peak, the divider factor must be changed; otherwise, the feedback/measured voltage will saturate the operational amplifier output, in the case of 180 volts peak to peak, the factor must be $a=1 / 18$

\section{RESULTS AND ANALYSIS}

The signal generator has been tested for different operating conditions required by the users, in which the converter is able to regulate the voltage at the output for different load values. In this case, the load will be resistive and variable in time, which for the tests carried out will change instantaneously.

The power converter, in buck configuration controlled with zero hysteresis, was built with the following parameters: an inductor of $L=179 \mathrm{mH}$ with an internal resistance of $3 \Omega$ and $C=2 \mathrm{nF}$. The load consists of two rheostats connected in series from 0 to $100 \Omega$ each, the switching frequency of the bridge reaches up to $10 \mathrm{kHz}$. This generator can follow different types of continuous and alternate signals, with certain limitations in terms of high frequencies and amplitude values close to the supply voltage $E$. Results are shown for some AC reference signals such as square, triangular and sinusoidal, varying frequency, amplitude, and disturbances in the load.

Figure 8 shows the output voltage as a sinusoidal signal of amplitude $15 \mathrm{~V}_{\text {peak }}$ and frequency of 60 $\mathrm{Hz}$ in the upper part of the diagram. Now, in the lower part of this figure, the reference signal is shown when with an amplitude of peak voltage of $15 \mathrm{~V}_{\text {peak }}$ with a frequency of $60 \mathrm{~Hz}$. Figure 9 shows the voltage output in the upper part of the diagram when the reference voltage in the lower part of the diagram is a triangular signal with a peak of $7.5 \mathrm{~V}$ and a frequency of $181.8 \mathrm{~Hz}$. 


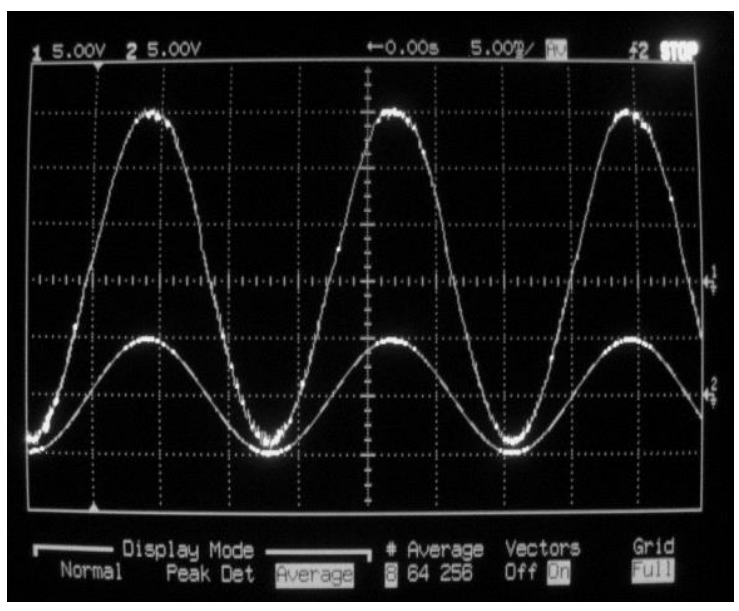

Figure 8. Sinusoidal signal of $60 \mathrm{~Hz}$. CH1: $v$ and $\mathrm{CH} 2$ : $v_{\text {ref }}$

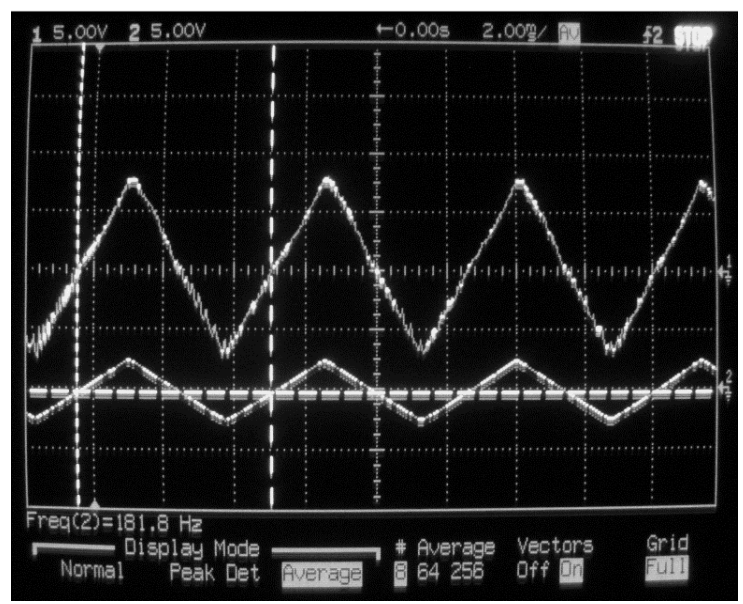

Figure 9. Triangular signal of $181.8 \mathrm{~Hz} . \mathrm{CH} 1: v$ and $\mathrm{CH} 2: v_{\text {ref }}$

Figure 10 shows the current in the load (upper graph) when the reference signal (lower graph) has a peak voltage value of $10 \mathrm{~V}$ and a frequency of $60 \mathrm{~Hz}$. Figure 11 shows the current in the inductance with the same operating conditions and with inverse polarity.

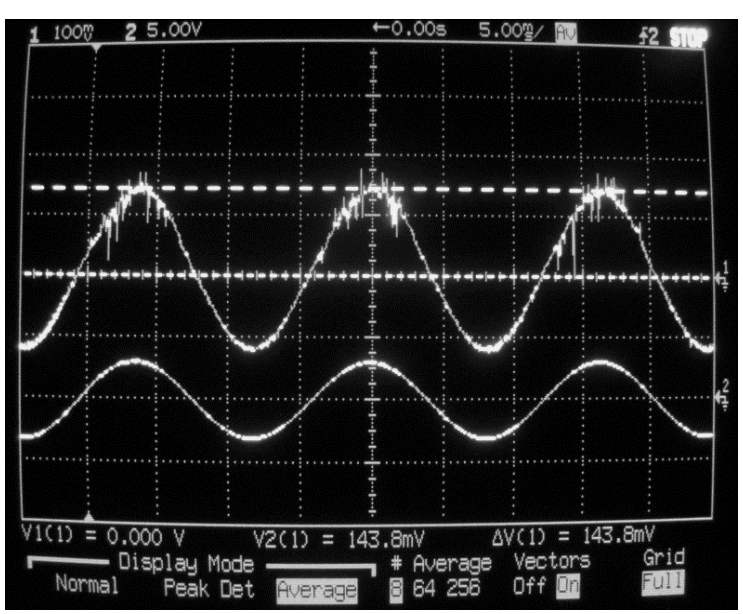

Figure 10. Current in the load. $\mathrm{CH} 1: i_{\mathrm{R}}$ and $\mathrm{CH} 2: v_{\text {ref }}$

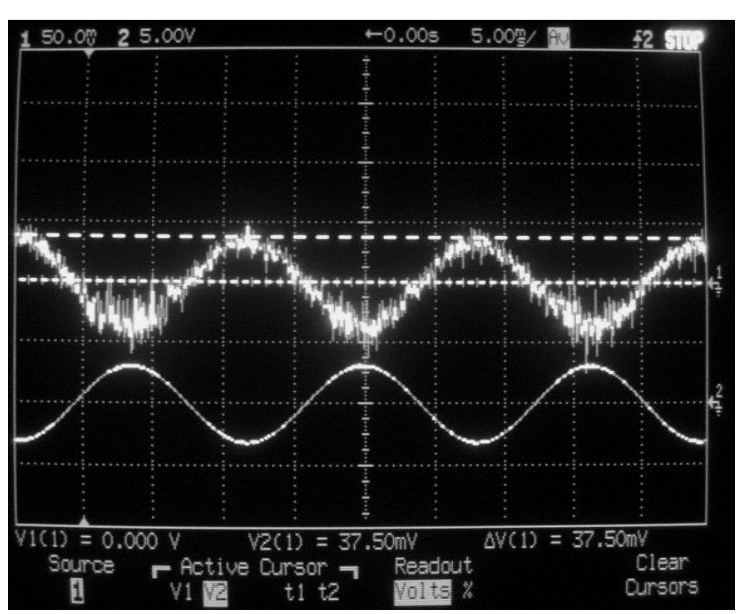

Figure 11. Current in the inductor. $\mathrm{CH} 1: i$ and $\mathrm{CH} 2: v_{\text {ref }}$

To verify the robustness of the system, in terms of voltage regulation at the output, disturbances are made in the load. Figure 12 shows the voltage and current in the load when the load changes from $200 \Omega$ to $100 \Omega$ and after a small period, the load of $200 \Omega$ is connected again. For this test, the reference signal to follow has a peak voltage of $5 \mathrm{~V}$ and a frequency of $50 \mathrm{~Hz}$. With the idea of perceiving the robustness of the system in terms of instantaneous variation of the reference signal, Figure 13 shows the voltage output in the load when changing the reference signal (square, sinusoidal, triangular) in small periods. For this case, the reference voltage has an amplitude of $5 \mathrm{~V}$ and a frequency of $1.020 \mathrm{~Hz}$.

Finally, Figure 14 shows the voltage at the output of the bridge (upper diagram) that feeds the buck converter and the voltage at the output after the filter (lower diagram), for a sinusoidal reference signal. It is important to note that the duty cycle of the PWM signals delivered by the bridge is not constant, and this varies depending on the operating conditions. 


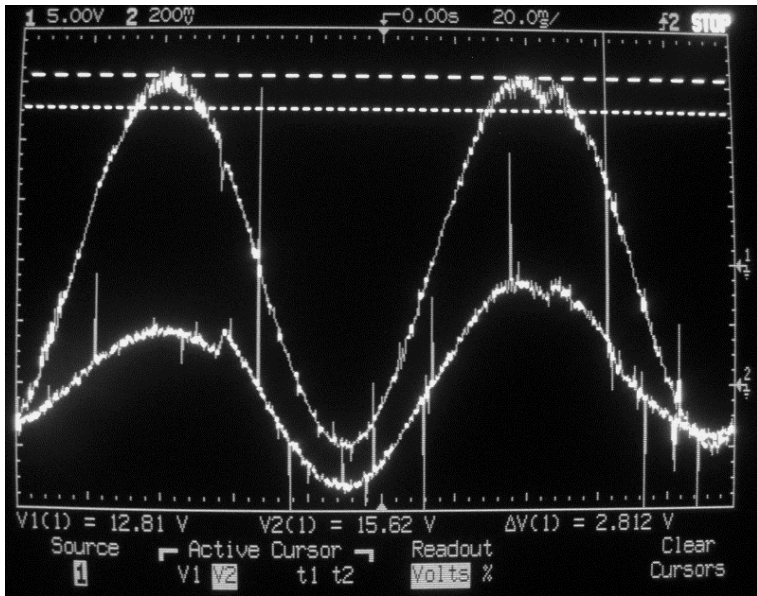

Figure 12. Load variation. $\mathrm{CH} 1: v$ and $\mathrm{CH} 2: i_{\mathrm{R}}$

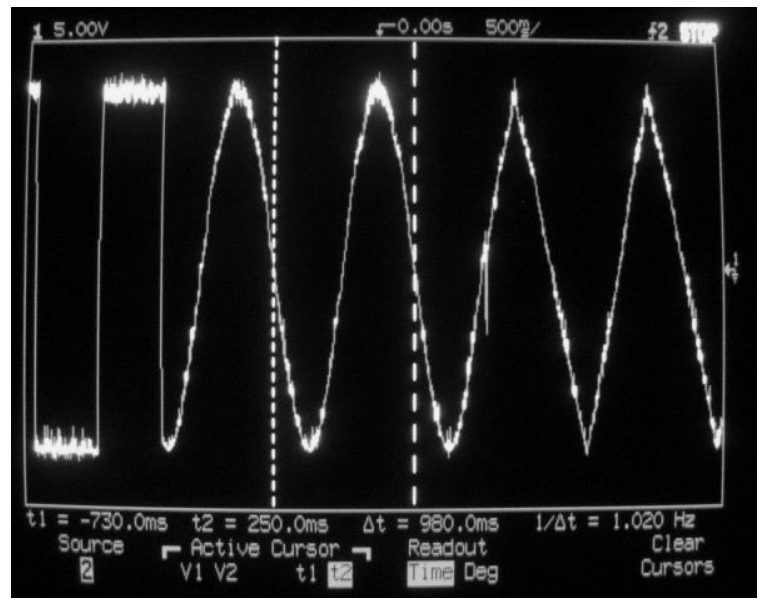

Figure 13. Varying the reference. $\mathrm{CH} 1: v$

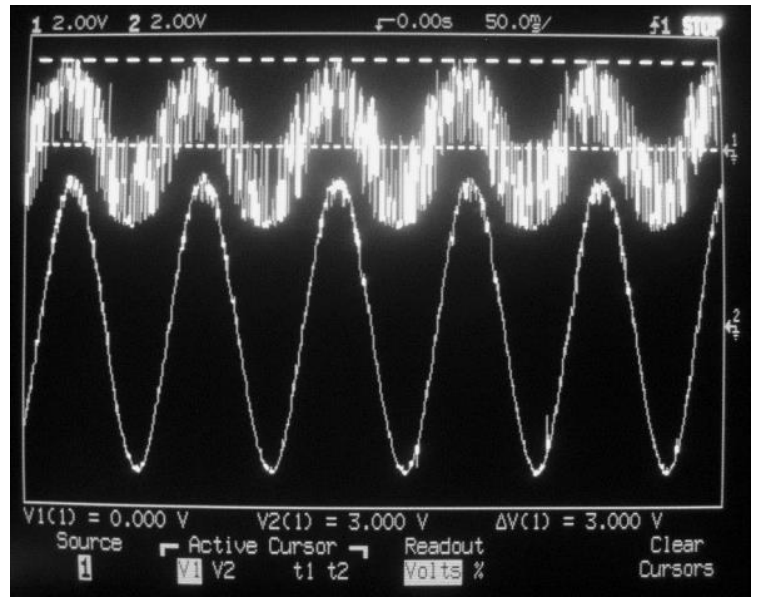

Figure 14. Voltage at the output of the bridge. $\mathrm{CH} 1$ : $\mathrm{PWM}$ and $\mathrm{CH} 2: v$

The prototype implemented has weaknesses in the regulation at high working frequencies, because the amplifiers introduce delays in the process. Another problem found in the developed prototype was that for amplitude values of the output signal near the $E$ voltage and with high frequencies, the $\mathrm{H}$ bridge presents a strong overheat which is caused by short circuits that are generated due to errors of the amplifiers.

\section{CONCLUSION}

A prototype of an electronic inverter controlled by zero hysteresis using analog electronics circuits has been designed, capable of generating output voltages of various shapes, including sinusoidal, triangular, square ramp and others, which handle powers up to $80 \mathrm{~W}$. The closed loop configuration and the control with zero hysteresis present proper operation and response to disturbances in the load. The system has a switching frequency of up to $10 \mathrm{kHz}$, which reflects the existence of a natural hysteresis and which, for fast response electronic devices such as TL084 amplifiers, offer a higher frequency of operation, achieving better regulation with less ripple.

From this work, new tasks are derived such as: to improve in terms of handling more power; managing to solve the problem of monitoring and regulating the signals at high frequency and amplitude, avoiding the overheating of the $\mathrm{H}$ bridge; to perform the design of a $\mathrm{H}$ bridge for higher voltage, in the order of $300 \mathrm{~V}_{\mathrm{DC}}$ to then be controlled with the same control technique and provide to the user with industrial output voltages less than $300 \mathrm{~V}$ variable in frequency and type of signal (square, triangular, sinus, ramp, DC); and to study the control by means of other digital control techniques with a DSP such as ZAD, FPIC, SMC, adaptive hysteresis and others that provide better regulation due to the processing speed. 


\section{ACKNOWLEDGEMENTS}

This work was supported by the Universidad Nacional de Colombia - Sede Medellín, under the projects HERMES-34671 and HERMES-36911. The authors thank the School of Physics, the Soil Microbiology Laboratory of the Faculty of Agrarian Sciences, and the Department of Electrical Energy and Automation of the Universidad Nacional de Colombia for the valuable help to conduct this research.

\section{REFERENCES}

[1] F. B. Cunha, et al., "Sliding bifurcations of equilibria in planar variable structure systems," IEEE Trans. Circuits Syst. I Fundam. Theory Appl., vol. 50, pp. 1129-1134, 2003.

[2] F. Angulo, "Análisis de la dinámica de convertidores electrónicos de potencia usando PWM basado en promediado cero de la dinámica del error (ZAD)," Universidad Politécnica de Cataluña, 2004.

[3] C. K. Tse, Complex Behavior of Switching Power Converters, 1st ed. Boca Raton, Florida: CRC Press, 2003.

[4] C. A. Ocampo, "Control de un conversor de potencia con modulador de ancho de pulso centrado usando modos deslizantes," Universidad Nacional de Colombia, Sede Manizales, 2003.

[5] R. Palanisamy, et al., "A Sub-Region Based Space Vector Modulation Scheme for Dual 2-Level Inverter System," International Journal of Electrical and Computer Engineering (IJECE), vol. 8, no. 6, pp. 4902, 2018.

[6] S. Suroso, et al., "Parallel Operation of Current-Source Inverter for Low-Voltage High-Current Grid-Connected Photovoltaic System," International Journal of Electrical and Computer Engineering (IJECE), vol. 9, no. 4, pp. 2220-2229, 2019.

[7] S. Suroso, et al., "New Dead-Time Compensation Method of Power Inverter using Carrier Based Sinusoidal PulseWidth Modulation," International Journal of Electrical and Computer Engineering (IJECE), vol. 8, no. 6, pp. 4880, 2018.

[8] F. E. Hoyos, et al., "Performance evaluation of a DC-AC inverter controlled with ZAD-FPIC," INGE CUC, vol. 14, pp. 9-18, 2018.

[9] D. W. Hart, Electrónica de potencia, Prentice Hall, 2001.

[10] N. Mohan, Advanced electric drives : analysis, control, and modeling using MATLAB/Simulink, Wiley, 2014.

[11] M. H. Rashid, Power electronics handbook: devices, circuits, and applications, Butterworth-Heinemann, 2011.

[12] J. A. Taborda, "Análisis de bifurcaciones en sistemas de segundo orden usando pwm y promediado cero de la dinámica del error," Universidad Nacional de Colombia - Sede Manizales, 2006.

[13] E. Fossas, et al., "Quasi-Sliding control based on pulse width modulation, zero averaged dynamics and the L2 norm," Advances in Variable Structure Systems - 6th IEEE International Workshop on Variable Structure Systems, pp. 335-344, 2000.

[14] F. Angulo, "Desarrollo de una nueva técnica de control para sistemas discretos," Universidad Nacional de Colombia, Sede Manizales, 2004.

[15] D. Biel, et al., "Programmable logic device applied to the quasi-sliding control implementation based on zero averaged dynamics," Proceedings of the 40th IEEE Conference on Decision and Control (Cat. No.01CH37228), vol. 2, pp. 1825-1830, 2001.

[16] C. I. H. Velasco, "Análisis de la dinámica no lineal de un convertidor buck controlado en tensión por banda de histéresis," Universidad Nacional de Colombia - Sede Manizales, 2007.

[17] J. A. Taborda, et al., "Quantization Effects on Period Doubling Route to Chaos in a ZAD-Controlled Buck Converter," Math. Probl. Eng., vol. 2012, pp. 1-19, 2012.

[18] A. E. Aroudi, et al., "Stabilizing a Two-cell DC-DC Buck Converter by Fixed Point Induced Control," Int. J. Bifurc. Chaos, vol. 19, pp. 2043-2057, 2009.

[19] E. Setiawan, et al., "Accurate Symbolic Steady State Modeling of Buck Converter," International Journal of Electrical and Computer Engineering (IJECE), vol. 7, no. 5, pp. 2374, 2017.

[20] J. Munoz, et al., "Boost converter control with ZAD for power factor correction based on FPGA," 2013 Workshop on Power Electronics and Power Quality Applications (PEPQA), pp. 1-5, 2013.

[21] O. A. Trujillo, et al., "PID controller using rapid control prototyping techniques," International Journal of Electrical and Computer Engineering (IJECE), vol. 9, no. 3, pp. 1645-1655, 2019.

[22] J. H. B. Deane and D. C. Hamill, "Analysis, simulation and experimental study of chaos in the buck converter," 21 st Annual IEEE Conference on Power Electronics Specialists, pp. 491-498, 1990.

[23] E. Fossas and G. Olivar, "Study of chaos in the buck converter," IEEE Trans. Circuits Syst. I Fundam. Theory Appl., vol. 43, pp. 13-25, 1996.

[24] Y. Z. TSypkin, Relay control systems, Cambridge University Press, 1984.

[25] IEEE Std. 1100-2005, "Recommended Practice for Powering and Grounding Electronic Equipment - Redline," IEEE, 2005. 


\section{BIOGRAPHIES OF AUTHORS}
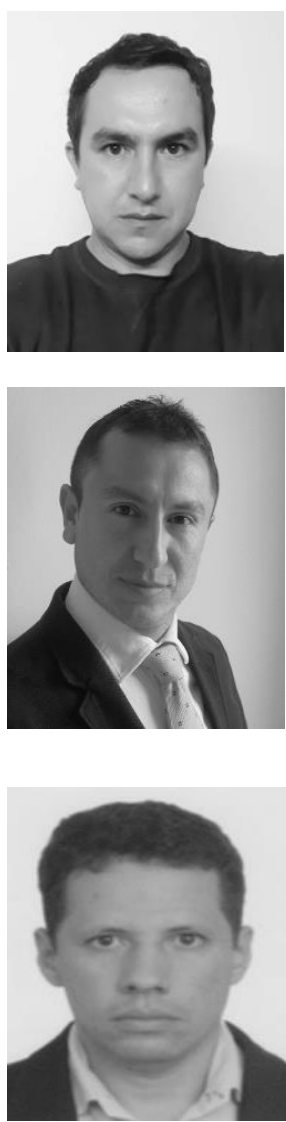

Fredy Edimer Hoyos: received his BS and MS degree from the National University of Colombia, at Manizales, Colombia, in Electrical Engineering and Industrial Automation, in 2006 and 2009, respectively, and Industrial Automation Ph.D. in 2012. Dr. Hoyos is currently an Associate Professor of the Science Faculty, School of Physics, at the National University of Colombia, at Medellin, Colombia. His research interests include nonlinear control, system modelling, nonlinear dynamics analysis, control of nonsmooth systems, and power electronics, with application within a broad area of technological process. Dr. Hoyos is an Associate Researcher in Colciencias and member of the Applied Technologies Research Group - GITA at the Universidad Nacional de Colombia. https://orcid.org/0000-0001-8766-5192.

Carlos I. Hoyos Velasco: received the degree (with honors) in Electronics Engineering and the Master's degree in Industrial Automation from National University of Colombia, at Manizales, Colombia, in 2005 and 2007, respectively. He received in 2011, his Ph.D. degree in Computer Science and Automatic Control from the University of Naples Federico II, Naples, Italy. He started his post-doc in 2012 at Istituto Motori of the National Research Council of Italy. His research interests include: model-based control, state observers design, physic-based modelling, nonlinear dynamic analysis, control tuning using bifurcations, power electronics and control of nonsmooth dynamical systems, with application within a broad area of automatic process, particularly automotive engineering and power electronics. Mr. Hoyos Velasco was a member of the IEEE Control System Society.

John E. Candelo-Becerra: received his Bs. degree in Electrical Engineering in 2002 and his $\mathrm{PhD}$ in Engineering with an emphasis in Electrical Engineering in 2009 from the Universidad del Valle, Cali - Colombia. His employment experiences include the Empresa de Energía del Pacífico EPSA, Universidad del Norte, and Universidad Nacional de Colombia - Sede Medellín. He is now an Associate Professor at the Universidad Nacional de Colombia - Sede Medellín, Colombia. His research interests include: engineering education; planning, operation and control of power systems; artificial intelligence; and smart grids. He is a Senior Researcher at Colciencias and member of the Applied Technologies Research Group - GITA, at the Universidad Nacional de Colombia. https://orcid.org/0000-0002-9784-9494. 